\title{
A Network-Based Telemetry Architecture Developed for the Martha's Vineyard Coastal Observatory
}

Thomas C. Austin, James B. Edson, Wade R. McGillis, Michael Purcell, Robert A. Petitt, Jr., Marguerite K. McElroy, Carlton W. Grant, Jonathan Ware, and Sheila K. Hurst

\begin{abstract}
Underwater observatories with real-time data and virtually unlimited power transmission capabilities compared to traditional oceanographic moorings are beginning to provide scientists with continuous access to the coastal and open ocean. However, for any coastal observatory to serve as a cost-effective system for the collection of long-term scientific and environmental data, it must have a simple, upgradeable power and telemetry system and an instrument interface that is compatible with existing standards. It must be designed for extended environmental exposure and ease of service to avoid high maintenance costs. Most importantly, the observatory must be accessible to all potential users, including students, scientists, engineers, and policy makers. This strategy was applied to the design of the Martha's Vineyard Coastal Observatory on the south shore of the island of Martha's Vineyard. The new facility, and in particular its system architecture, as developed by the Woods Hole Oceanographic Institution with support from the National Science Foundation, are described.
\end{abstract}

Index Terms-Atmospheric measurements, data communications, marine technology, sea coast, sea floor measurements, sea measurements, underwater communication cables.

\section{INTRODUCTION}

$\mathbf{C}$ OASTAL processes are of crucial societal and environmental importance. Engineers and planners are concerned with coastal protection, particularly in heavily populated areas where wave attack, setup, and shoreline erosion threaten coastal structures. Geologists are struggling to understand how the astonishing variety of coastal geological features form and evolve in response to nearshore processes. Coastal meteorologists are only now beginning to investigate physical processes that are unique to the coastal environment, including the adjustment of the near-surface flow to extreme changes in the surface roughness, differential heating, and extensive sea-spray production in the surf zone.

WHOI scientists and their colleagues have been involved in coastal and nearshore field studies ranging from investigations of the flow structure measured in the atmospheric [1] and bottom boundary layers [2]; waves in the shoaling [3], surf [4] and swash [5] zones; and nearshore morphological changes at scales ranging from sand bars [6] to orbital ripples [7]. To date, none of these studies has taken advantage of Cape Cod and the Islands' southward facing Atlantic coastlines. This is partly due to the

\footnotetext{
Manuscript received March 4, 2001; revised January 24, 2002. This work was supported by the National Science Foundation under Grant OCE-9871120 and the Woods Hole Oceanographic Institution. WHOI contribution number 10603.

The authors are with the Department of Applied Ocean Physics and Engineering, Woods Hole Oceanographic Institution, Woods Hole, MA 02543 USA (e-mail: taustin@whoi.edu).

Publisher Item Identifier S 0364-9059(02)03365-4.
}

lack of exposure of this shoreline to the open ocean due to the protection of Nantucket, Martha's Vineyard, and the Elizabeth Islands. As a result, the nearshore studies that have been conducted in this region must be satisfied with a fetch-limited wave field under most conditions.

In contrast, using both coastal research vessels and ground transportation, researchers are able to obtain easy access to the unprotected southward-facing shore of Martha's Vineyard, allowing nearshore processes to be investigated locally. The approximately 25-km southern shoreline of Martha's Vineyard is nearly straight with homogeneous alongshore topography. The shoreline faces the predominant southwesterly winds from the open ocean. Waves and currents cause beach erosion and sediment transport that results in an average of $2-3 \mathrm{~m}$ of shoreline retreat each year. The orientation of the shoreline allows the effects of winds, waves, and currents on the coastline to be observed in mild to severe conditions and thus provides a natural laboratory to study nearshore hydrodynamics, sediment transport, biological and benthic processes, gas transfer, aerosol physics, and coastal meteorology.

To take advantage of this shoreline and its research opportunities, WHOI built the Martha's Vineyard Coastal Observatory (MVCO) near South Beach in Edgartown, Massachusetts [8]. Scientists in the Coastal and Ocean Fluid Dynamics Laboratory (COFDL) initiated the project at WHOI. These and other scientists are now using the observatory to study coastal atmospheric and oceanic processes. Specifically, the observatory is being used to:

- provide a local climatology for intensive, short duration field campaigns;

- further facilitate additional studies of coastal processes by providing infrastructure that supports easy access to electrical power and data;

- provide a reliable system of rugged sensors that allow sampling of extreme events;

- provide continuous long-term observations for climate studies using structures that can withstand severe conditions for a minimum of 25 years.

- provide a flexible system capable of supporting a wide range of instrumentation and platforms, such as AUV docking stations;

- provide a test facility for instrumentation destined for other applications such as rugged sensors for extreme conditions and sensor packages intended for deep sea observatories;

- provide a means for public outreach and educational programs; 


\section{Martha's Vineyard Coastal Observatory}
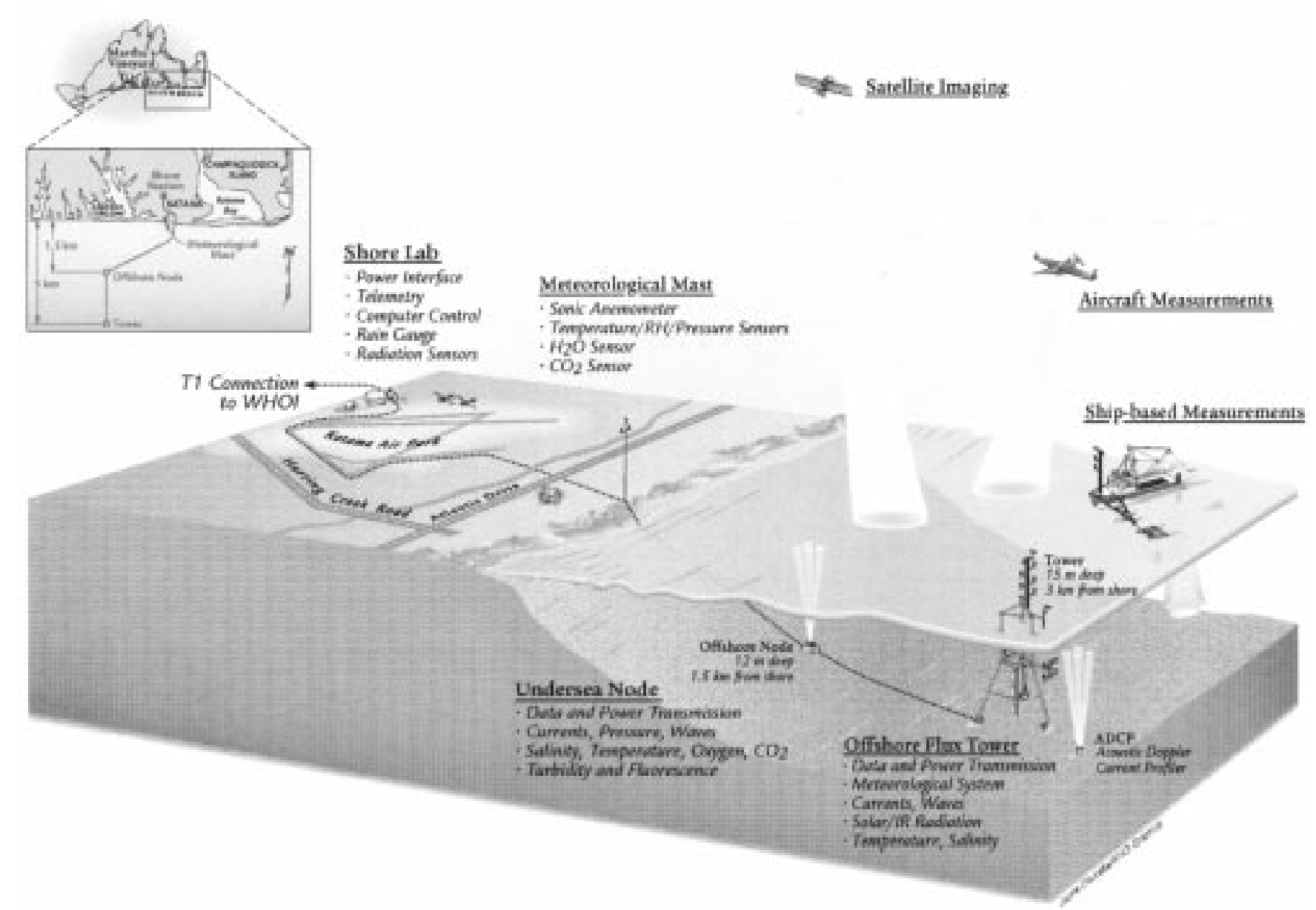

Fig. 1. Location and layout of the MVCO showing the cable routes and node locations. The dashed lines indicate the proposed location for the offshore tower.

- contribute to a larger network of observatories and platforms for real-time observations that can help verify and improve ocean and atmospheric models.

\section{SYSTEM DESCRIPTION}

Engineers in the Oceanographic Systems Laboratory (OSL) at WHOI are primarily responsible for the design and construction of the observatory along the southern shoreline of Martha's Vineyard. Due to its unprotected exposure to the predominant southwesterly winds, the MVCO provides a unique setting on the east coast to investigate coastal processes. Studies at MVCO will complement research conducted at existing observatories along the eastern seaboard where onshore winds are normally associated with easterlies. During the winter months, the shoreline is routinely exposed to severe coastal storms that are of particular interest to the scientists involved in this project. Design of this system has benefited greatly from the lessons learned and successful work accomplished at LEO-15 [9].

The MVCO includes a small shore lab located $1.5 \mathrm{~km}$ inland, a 10-m meteorological mast $50 \mathrm{~m}$ inshore of the shoreline and a subsurface node mounted on the seafloor in $12 \mathrm{~m}$ water depth, $1.5 \mathrm{~km}$ offshore (Fig. 1). Here, node refers to the electrical and structural components that support the instrument packages. The meteorological and subsea nodes and associated instrumentation are connected directly to the shore lab via an embedded electrooptic power cable. The site for the meteorological mast is particularly attractive because the gentle topography at the beach allows sensor deployment above the flow disturbance generated by the dunes. This places the fast response instruments in marine air for onshore winds, which provides direct measurements of the turbulent exchange of momentum, heat and mass between the atmosphere and coastal ocean.

The core set of sensors at the meteorological mast measure wind speed and direction, temperature, pressure, humidity, $\mathrm{CO}_{2}$, and momentum, heat, and moisture fluxes. The mast also supports a camera to visually monitor the nearshore region. Sensors at the shore lab measure precipitation, solar and IR radiation, wind speed, wind direction, temperature, and humidity. Oceanographic sensors at the offshore node measure current profiles, waves, tides, temperature, salinity, turbidity, fluorescence, $\mathrm{pH}$, and dissolved oxygen. Additional information about the specific sensors is provided in the sections that follow.

Besides the core set of instruments, the offshore node and the meteorological mast act as extension cords into the coastal environment because they allow connection of a wide range of 
instruments for prolonged deployments. The node architecture was designed to allow simple integration of any sensor by implementing a standard guest port configuration. Each guest port provides a flexible DC power interface and a choice of data interfaces, including Ethernet, RS-232 and RS-422 communication options. The observatory is connected to the WHOI network via a high-speed network communications link.

The first phase of the MVCO, the lab, meteorological mast, and offshore node, became operational by June 2001 and public access to the data is now available over the Internet. The system is designed to be expandable, with spare power and fiber-optic connections provided for future nodes. For example, in the near future we plan to deploy an additional node farther offshore (Fig. 1). This node will provide power and data access to instruments deployed on an air-sea interaction tower (ASIT) that will span the coupled boundary layers from the ocean bottom at a depth of approximately $15 \mathrm{~m}$ to a height of approximately 15 $\mathrm{m}$ above the sea surface.

\section{A. Shore Laboratory}

WHOI has leased space at the publicly owned Katama Air Park, which is a grass strip airfield located in Edgartown, MA and constructed a small, unmanned shore laboratory at the site. The airfield provides a safe, secure location for the shore-based laboratory with proximity to power and telecommunication services. The shore laboratory is the termination point for the fiberoptic/power cable and contains the computer systems and power supplies necessary for controlling the sensors and logging the data locally. A 10-m mast extending above the laboratory holds sensors to measure solar and infrared radiation (Eppley PSP and PIR radiometers), rainfall rate (RM Young Tipping Bucket Rain Gauge), temperature, humidity (Vaisala HMP45), wind speed, and direction (RM Young Wind Monitor). The shore laboratory is connected to WHOI via a T-1 data line with a $56-\mathrm{Kb} / \mathrm{s}$ leased-line as back up. Provisions have been made for a possible future upgrade of the backup system to a wireless $11-\mathrm{Mb} / \mathrm{s}$ data link. The laboratory includes an automatic, backup-power generator to continue operation of the entire system during power outages. All computer and equipment operations are monitored remotely from WHOI.

\section{B. Cable Description and Installation}

The main cable design consists of six AWG13 copper power conductors, with high-voltage insulation. Ten single-mode optical fibers are contained in a loose-tube assembly at the center of the cable. The core is jacketed with a polyurethane sheath protected by two layers of cross-laid armor wire and a polyethylene outer jacket. The cable has a maximum working load of $3180 \mathrm{~kg}(7000 \mathrm{lb})$, which is well above the loading experienced during the cable installation process.

To cross the beach area with the least environmental impact, WHOI utilized directional drilling technology. This technology, originally developed for use in oil fields, is now within economic reach of science and has been used at both LEO-15 and MVCO. In both cases the permitting process for the shore approach through wildlife sanctuaries was facilitated by the use of this environmentally sensitive method [10]. The drilling operation, accomplished in May 2000, provided a sleeved hole, $626 \mathrm{~m}$ in length, between the airfield and the seafloor (approximately $300 \mathrm{~m}$ from the beach). A second conduit (206 $\mathrm{m}$ in length) was drilled to provide a cableway to the meteorological sensor mast located on the beachfront.

The seafloor cable is buried 1 to $2 \mathrm{~m}$ below the seabed, from the offshore end of the drilled section to the location of the offshore node. The cable route was chosen to place the offshore node closer to the center of the island's coastline as shown by the insert in Fig. 1. This choice positions the sensors in a region of more uniform bottom topography at a location that is upwind of the meteorological sensors for southwesterly winds.

\section{Seafloor Node}

The MVCO now includes one seafloor node, with another planned for the near future. The seafloor node is constructed on a pedestal base that has been permanently jetted into the seabed at the offshore site. The pedestal supports the instrument frame at a distance of approximately $0.5 \mathrm{~m}$ above the bottom. This change from the bunker-style node used at LEO-15 allows sand to propagate beneath the node, which limits the accumulation of sand within the frame. This is also expected to mitigate the problem of scouring beneath the node.

The node contains twenty guest ports that are available to the users via a simple 8-pin underwater-matable connector. Each port provides electrical connections for two isolated DC power supplies and a remotely programmable data interface allowing Ethernet, RS-232, or RS-422 connections. The electronics housing shown in the schematic (Fig. 2) contains all necessary power and telemetry circuits. The guest port connectors are jumpered to a connector panel that is easily accessible to divers.

The neutrally buoyant instrument frame, which is the upper section of the node, is easily recovered for routine maintenance and upgrades. The lower frame houses an oil-filled transformer box, which contains the three step-down transformers that are hard-wired to the main cable. Diver-matable fiber-optic and electrical connectors mounted on the transformer box provide access to the main cable's optical fibers and the stepped-down power from the transformers. When the upper instrument frame is recovered, divers detach the fiber-optic and power connectors, leaving the transformer box on the pedestal.

The seafloor node is equipped with a core set of sensors including a 1200- kHz Acoustic Doppler Current Profiler (ADCP) (RD Instruments Workhorse ADCP Wave gauge) to provide velocity profiles and directional wave spectra, a Paroscientific high-resolution pressure sensor that can function as a tide gauge, and an oceanographic sensor suite (YSI 6600) that monitors a wide range of water properties including temperature, salinity, turbidity, $\mathrm{pH}$, fluorescence, and dissolved oxygen.

\section{Meteorological Sensor Mast}

A 10-m meteorological sensor mast is located on the beachfront, approximately $60 \mathrm{~m}$ from the mean low-water mark, just behind the present location of the dunes. The second branch of the cable route is connected to an electronics housing at the base of the mast. The guest ports and power and telemetry circuits in this housing are nearly identical to those in the offshore node. The mast rises approximately $8 \mathrm{~m}$ above the dunes and $13 \mathrm{~m}$ above mean sea level. 


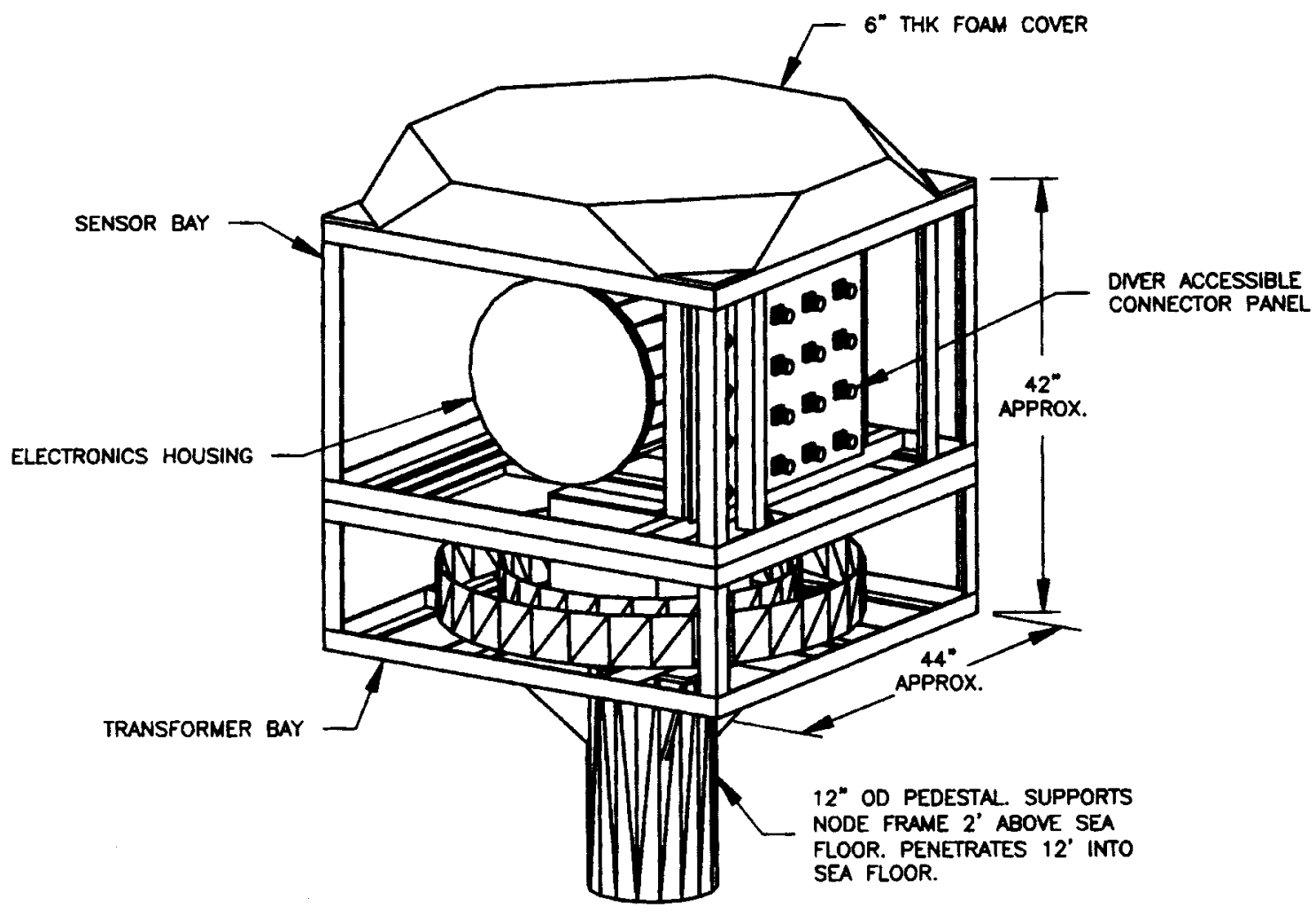

Fig. 2. Schematic of the MVCO seafloor node.

The mast has a core set of fast response sensors that include a three-axis ultrasonic anemometer (Solent R3), which also provides fast-response temperature measurements derived from its sound speed measurements and an infrared hygrometer/ $/ \mathrm{CO}_{2}$ sensor (LI-COR 7500). Additional sensors measure the mean wind speed and direction (Solent Wind Observer), relative humidity, temperature, and pressure (Vaisala PTU200). The electronics housing at the mast also includes a number of extra guest ports that are available for general use. A camera is mounted on the mast to visually record cloud coverage and surface wave conditions in its field of view.

Our initial investigations show that the height of the mast places the sensors above the internal boundary layer and most of the flow distortion induced by the shoreline transition, beach and dunes [11]. For example, our estimates of the neutral drag coefficient indicate that the sonic anemometer accurately measures the transfer of momentum and heat between the atmosphere and the coastal ocean when winds are onshore. This claim is based on the agreement found between our estimates of the drag coefficient and those computed using the TOGA-COARE 2.6 bulk formula [12] as shown in Fig. 3. Ongoing investigations will attempt to quantify and remove the remaining effects of flow distortion that are present at the sensor locations atop the mast.

\section{POWER SYSTEM}

In the previous system developed at WHOI for LEO-15, three-phase ac power was transmitted in the cable. This power is then stepped-down and rectified to $120 \mathrm{~V}$ or $240 \mathrm{~V}$ dc for distribution at the node. The MVCO design used a different

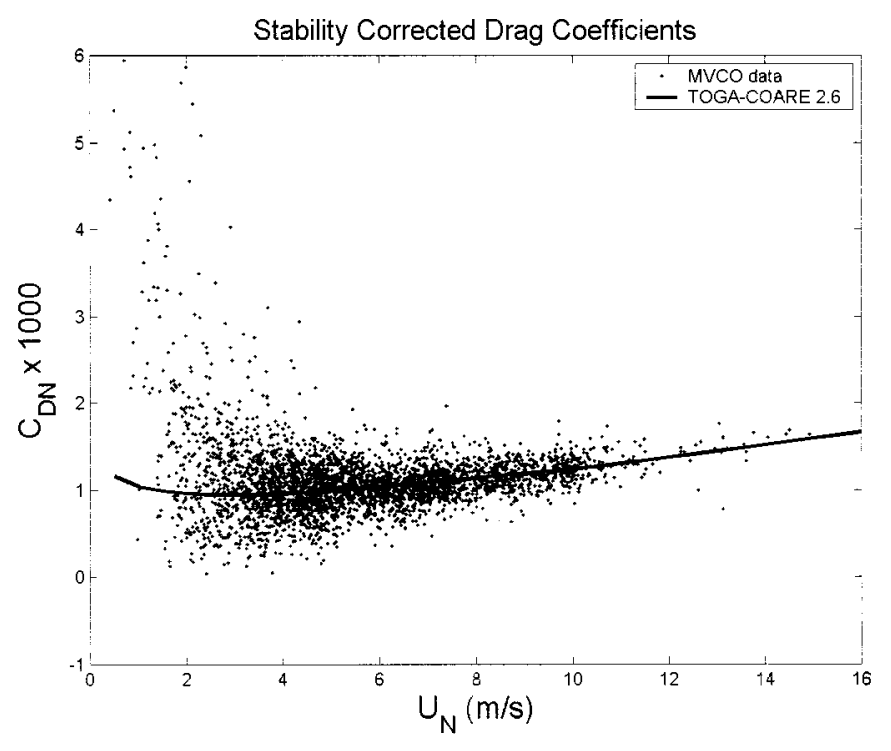

Fig. 3. Neutral drag coefficients plotted as a function of wind speed.

approach. First, three separate single-phase circuits were implemented rather than one common three-phase circuit. This was made possible by a new cable design that included six, rather than three, conductors. These six conductors provide for three independent power circuits offshore.

The use of single-phase power did not require any major modifications to the single-phase utility service at the shore laboratory, so the power is directly provided by the local utility. A propane-power generator backup and an uninterruptible power source (UPS) are used to maintain seamless power 
TABLE I

PIN ASSIGNMENTS FOR THE GUEST PORTS

\begin{tabular}{l|l}
\hline Pin 1: & $12 \mathrm{~V}+(100$ Watts max $)$ \\
\hline Pin 2: & $\begin{array}{l}12 \mathrm{~V} \mathrm{Common} \mathrm{(Data} \\
\text { Common) }\end{array}$ \\
\hline Pin 3: & $24 \mathrm{~V}+(100$ Watts max $)$ \\
\hline Pin 4: & $24 \mathrm{~V}$ Common \\
\hline Pin 5: & Data TX+ (RS-232 TX) \\
\hline Pin 6: & Data TX- \\
\hline Pin 7: & Data RX+ (RS-232 RX) \\
\hline Pin 8: & Data RX- \\
\hline
\end{tabular}

transfer during local outages. The automatic generator/UPS combination maintains data collection capability even during severe storm events. The use of the single-phase utility service also allows us to directly power the $240-\mathrm{V}$ ac installation at the meteorological mast, which has its own cable and does not require an external transformer.

The six AWG13 power conductors in the seafloor cable have insulation ratings of $2500 \mathrm{~V}$. This allows us to transmit power from the shore laboratory at $1500 \mathrm{Vrms}$, using a step-up transformer and single-phase $60 \mathrm{~Hz}$ ac. At the seafloor node, the high-voltage AC in the three circuits is stepped down to $240 \mathrm{~V}$ ac using transformers. The ac distribution technique was chosen to simplify the wiring in both the oil-filled transformer box and the electronics housing. The commercial Ethernet hardware and the electronic power supplies are directly connected to the ac input inside the electronics housing. Using this approach, each circuit is capable of providing $4 \mathrm{~kW}$ of power to a distance of up to $5 \mathrm{~km}$ from shore.

Initially, only one of the three circuits will be utilized for power to the seafloor node, with the other two circuits reserved for future offshore nodes. This $240-\mathrm{V}$ ac supply is fed into the main electronics bottle where it is converted to regulated DC power required by each of the guest port boards. Each guest port board uses on-board rectifier and bulk capacitors to provide the ac-dc input power conversion required for the user power supplies. Two separate Vicor 2nd Generation Micro-Modules provide $12-\mathrm{V}$ dc and $24-\mathrm{V}$ dc outputs at up to $100 \mathrm{~W}$ each $(200 \mathrm{~W}$ total) at every guest port (Table I).

Power supply isolation is maintained between ports, allowing for independent ground fault sensing of each port. Each guest port is monitored and controlled by a local Motorola $68 \mathrm{HC} 11$ micro controller. This controller can connect or disconnect the ac input for that port and power-on or -off the two dc outputs using remote commands over the network. In addition, the micro controller monitors voltage, current and ground fault status for both the $12-\mathrm{V} \mathrm{dc}$ and the $24-\mathrm{V} \mathrm{dc}$ power supply outputs. The port is normally configured to automatically shut down power to a guest port in the event that a fault is detected, thus preventing further damage. By using these isolated power supplies for each port, power problems on one port do not affect any other ports.

\section{NeTworked Data TELEMETRY}

The power/data block diagrams for the shore laboratory and seafloor node are shown in Figs. 4 and 5, respectively. Because all of the sensor nodes are network connections, all nodes are simply connected together on a common Ethernet network inside the shore laboratory at the Katama Airpark. The seafloor node electronics and the meteorological mast data telemetry electronics are essentially identical. Each node is connected to the shore laboratory by a 1 Gigabit/sec Ethernet fiber-optic trunk line with ac power. A Cisco Systems Ethernet switch provides 24 10/100 BaseT Network connections at the nodes and the shore laboratory. Each switch contains a single-mode fiber-optic networking module as well as the $24 \mathrm{RJ}-45$ twisted pair connectors. The buried fiber-optic cables are connected directly to the Cisco Ethernet switch to transmit the networked data at $1 \mathrm{~Gb} / \mathrm{s}$ to and from the shore laboratory. This network is connected to the global Internet via the $\mathrm{T}-1$ data line with the $56-\mathrm{Kb} / \mathrm{s}$ leased line serving as back up as shown in Fig. 4.

We expect that many of the scientific instruments connected to the guest ports will initially utilize asynchronous serial communication interfaces such as RS-232 to control the instruments and collect data. Therefore, a method was needed to integrate multiple serial ports into the Ethernet data system. This function is provided by a Cisco Systems serial communications server, which supplies 16 serial ports for distribution among the various user ports (Fig. 5). The communications server has an Ethernet interface that connects to one of the network ports on the Ethernet switch. It allows direct IP, telnet, or COM-port redirection access to any of its serial ports, thus allowing users to access their underwater instrument from anywhere on the Internet. The commercial-off-the-shelf technology for data telemetry now available has made this system much more flexible than was possible when LEO-15 was designed. As the technology continues to evolve the network equipment can easily be replaced or upgraded without major system modification.

\section{GUEST PORT INTERFACE}

At each node there are a number of identical guest ports. The seafloor and meteorological mast nodes support 20 and 10 ports, respectively. Each port is assigned an 8-pin connector (Impulse IE8F underwater-matable at the seafloor node). The pin assignments for the 8-pin connector are given in Table I. The data lines are remotely programmable for one of three interfaces: 10/100BaseT Ethernet, RS-232, or RS-422. The RS-232 and RS-422 baud rates are supported up to $115 \mathrm{kbps}$. The data common (RS-232 and RS-422 only) is connected to the $12-\mathrm{V}$ common pin. The Ethernet interface is connected to the Ethernet switch, which in turn routes all data traffic over the fiber-optic cable to the shore lab, where it is then routed to WHOI and the World Wide Web over the T-1 link.

The RS-232 or RS-422 serial ports are accessible via the Ethernet using TELNET, custom software (direct IP), or commercial COM-Port redirection software provided to the users. The COM-Port redirection software allows users to run existing applications that normally connect to a local COM-Port. The software automatically redirects the transmitted and received messages to and from the remote port over the Ethernet. For low-speed serial ports, this works across the Internet. However, we expect most users will store data locally and access data remotely. 


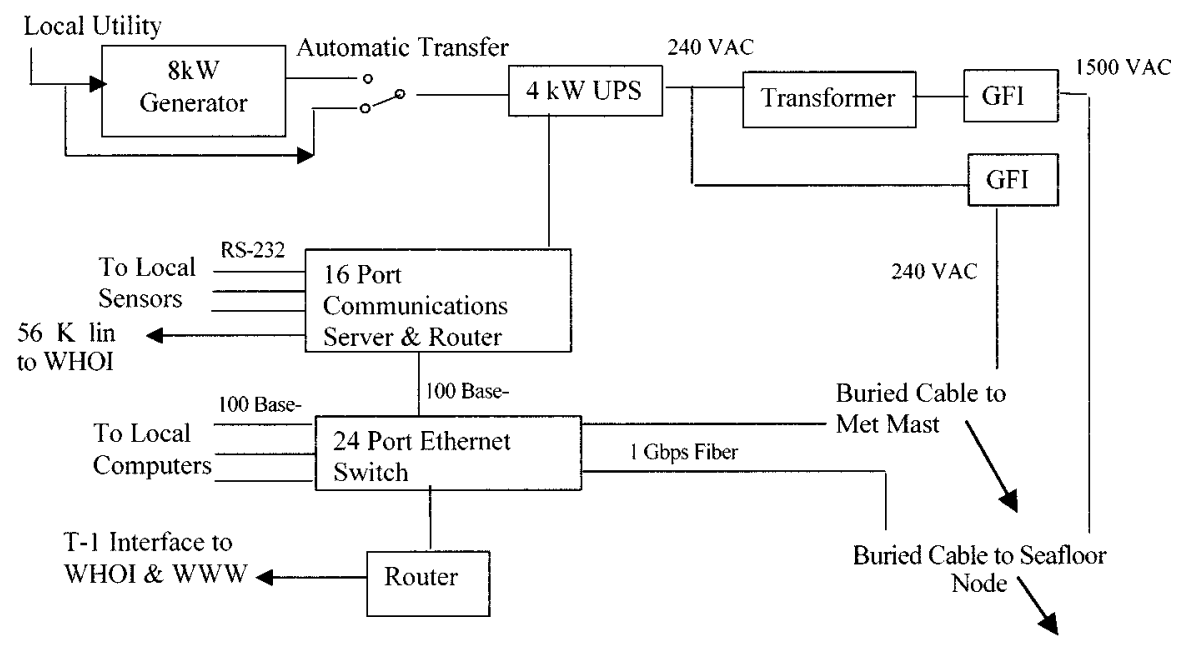

Fig. 4. MVCO shore lab power/data block diagram. The blocks denoted by GFI represent ground fault indicators.

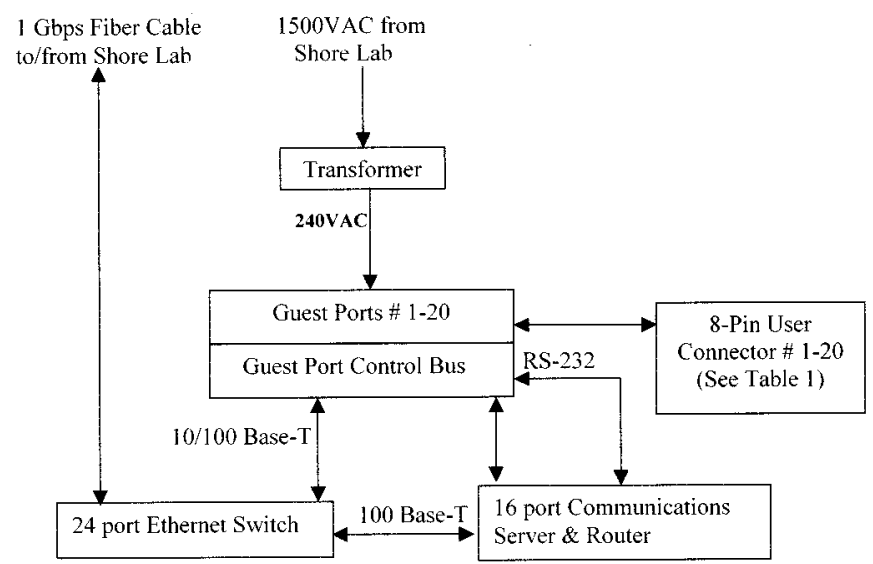

Fig. 5. MVCO seafloor node power/data block diagram. (Met-Mast Node is identical except that there are 10 quest ports and there is no transformer).

Users are given an IP address that provides access to their assigned guest port. In the future, users will be provided with a password-protected Web page for control of their assigned port. This Web page is under development and will include on/off controls for each power supply, as well as voltage and current gauges, ground fault gauges and a check box table to select the interface type [13]. All ports are automatically monitored for fault conditions, including over-current, ground faults, and data type violations (i.e., RS-232 levels detected while RS-422 interface was selected). If a fault is detected, the port is automatically shut down, with no effect on any other ports. In the future, the user may elect to override the fault condition at their discretion, by selecting the "fault override" control on that port's web interface.

In addition to the existing network connections and serial ports available, there are multiple unclaimed single mode optical fibers between the shore lab and all sensor nodes, which are available for users with special data requirements.

\section{SUMMARY}

The MVCO has recently been installed off of the south coast of the island to monitor coastal atmospheric and oceanic conditions. This observatory provides scientists with direct access to the coastal environment and allows continuous measurements of environmental parameters under all conditions, including severe storms of the North Atlantic. Based on long experience with a wide variety of underwater instrument deployments and by implementing a telemetry system that will be simple to upgrade using commercially available technology, the observatory has been designed to be in operation for a minimum of 25 years with minimal maintenance. Generic user guest ports provide simple connection for all types of instrumentation using conventional power and data interfaces. Spare power conductors and optical fibers in the main cable provide for significant expansion capability for future offshore nodes, AUV docking stations, and other special experiments.

\section{ACKNOWLEDGMENT}

The authors thank the Town of Edgartown, MA, for their support throughout the permitting and installation phases of this project. In particular, they thank R. Stone (Chairman, Edgartown Airport Commission), R. Nutting (Manager, Katama Air Park), and J. Varkonda (Conservation Agent, Town of Edgartown) for their support and efforts on this project.

\section{REFERENCES}

[1] L. Mahrt, D. Vickers, J. Edson, J. Sun, J. Højstrup, J. Hare, and J. M. Wilczak, "Heat flux in the coastal zone," Bound.-Layer Meteorol., vol. 86, pp. 421-446, 1998.

[2] S. J. Lentz and J. H. Towbridge, "The bottom boundary layer over the northern california shelf," J. Phys. Oceanog., vol. 21, pp. 1186-1201, 1991.

[3] S. Elgar and R. T. Guzag, "Observations of bispectra of shoaling surface gravity waves," J. Fluid Mech., vol. 161, pp. 425-448, 1985.

[4] Y. Chen, R. T. Guza, and S. Elgar, "Modeling breaking surface waves in shallow water,” J. Geophys. Res., vol. 102, pp. 25 035-25 046, 1997.

[5] B. Raubenheimer, R. T. Guza, S. Elgar, and N. Kobayashi, "Swash on a gently sloping beach,” J. Geophys. Res., vol. 100, pp. 8751-8760, 1995.

[6] E. Gallagher, S. Elgar, and R. T. Guza, "Observations of sand bar evolution on a natural beach," J. Geophys. Res., vol. 103, pp. 3203-3215, 1998.

[7] P. Traykovski, A. E. Hay, J. D. Irish, and J. F. Lynch, "Geometry, migration and evolution of wave orbital scale ripples at LEO-15," J. Geophys. Res., vol. 104, pp. 1505-1524, 1999.

[8] J. B. Edson, W. R. McGillis, and T. C. Austin, "A new coastal observatory is born," Oceanus, vol. 42, pp. 31-33, 2000. 
[9] N. C. Forrester, R. P. Stokey, C. J. von Alt, B. G. Allen, R. G. Goldsborough, M. J. Purcell, and T. C. Austin, "The LEO-15 long term ecosystem observatory: Design and installation," in Proc. Oceans '97, vol. 2, Halifax, Canada, pp. 1082-1088.

[10] M. K. McElroy, J. B. Edson, T. C. Austin, W. R. McGillis, and M. J. Purcell, "Underwater observatories: The challenges and promise of applying off-shore cable technology to long-term environmental studies," in Proc. Underwater Intervention-2001, Houston, TX, Jan. 21-27, 2001.

[11] N. O. Jensen and E. W. Peterson, "On the escarpment wind profile," Quart. J. R. Metereol. Soc., vol. 104, pp. 719-728, 1978.

[12] C. W. Fairall, E. F. Bradley, D. P. Rogers, J. B. Edson, and G. S. Young, "Bulk parameterization of air-sea fluxes for TOGA COARE," J.Geophys.Res., vol. 101, pp. 3747-3764, 1996.

[13] R. P. Stokey, "Web-centric instrumentation: Controlling and monitoring a vertical profiler using a WWW browser," in Proc. Oceans 2000, vol. 1, Providence, RI, pp. 349-352.

Thomas C. Austin received the B.A. degree from the University of Vermont, Burlington, and the B.S. and M.S. degrees in electrical engineering from Northeastern University, Boston, MA.

He has served as Chief Engineer at Benthos, Inc., and currently holds an appointment as Senior Engineer in the Oceanographic Systems Lab at Woods Hole Oceanographic Institution, Woods Hole, MA. His research interests include development of instrumentation for transmission and reception of underwater acoustic signals, acoustic navigation, power, propulsion, control and communication systems for autonomous and remotely operated vehicles, digital signal processing, and hydrophone design. He served as Chief Engineer and project manager as well as developing the instrument interface, data telemetry and control systems for the Martha's Vineyard Coastal Observatory.

James B. Edson received the B.S. degree in physics from Dickinson College, Carlisle, PA, in 1984 and the Ph.D. degree in meteorology from the Pennsylvania State University, State College, in 1989.

He spent a year and a half as a Visiting Scientist at the Ecole Nationale Supérieure de Mécanique, Nantes, France, before joining the scientific staff in the Applied Ocean Physics and Engineering Department at the Woods Hole Oceanographic Institution, Woods Hole, in 1991. His research interests lie in boundary layer meteorology with a focus on atmospheric turbulence and air-sea interactions. The objective of his research is to improve our understanding of processes associated with the transfer of heat, mass and momentum across the coupled boundary layers. Since 1998, he and Wade McGillis have acted as Chief Scientists on the Martha's Vineyard Coastal Observatory.

Wade R. McGillis received the B.S. degree in mechanical engineering from Northeastern University, Boston, MA, in 1988 and the Ph.D. degree from the University of California at Berkeley in 1993.

He was a post-doctoral scholar and investigator in the Applied Ocean Physics and Engineering Department at the Woods Hole Oceanographic Institution, Woods Hole, MA, for several years before joining the scientific staff in 1996. His research interests lie in coupled atmosphere-ocean processes, air-water carbon dioxide and water vapor fluxes, and interfacial hydrodynamics. The objective of his research is to improve our understanding of processes controlling the global carbon cycle. He has acted as co-Chief scientist on the Martha's Vineyard Coastal Observatory and has assisted in the design, selection, and implementation of all scientific instrumentation of the Martha's Vineyard Observatory.
Michael Purcell received the B.S. degree in ocean engineering from the Florida Atlantic Univerisity in 1980 and the M.S. degree in ocean engineering from the Massachusetts Institute of Technology, Cambridge, in 1984.

He currently holds an appointment as a Senior Engineer in the Oceanographic Systems Lab at Woods Hole Oceanographic Institution, Woods Hole, MA. His research interests include the design of underwater vehicles and instruments, development of cable handling systems, dynamics of moorings, tethered vehicles and AUVs, and the design of a particle measurement system for the marine atmosphere. He served as Chief Mechanical Engineer for the Martha's Vineyard Coastal Observatory project and designed and oversaw the deployment of the structures holding the instrument packages at the meteorological mast and offshore nodes

Robert A. Pettit, Jr. received the B.S. degree in physics from the State University of New York at Albany in 1982 and the M.S. degree in electrical engineering from the Polytechnic University in 1989.

He currently holds an appointment as a Research Engineer in the Advanced Engineering Lab at the Woods Hole Oceanographic Institution, Woods Hole, MA. His research interests include low-power, precision instrumentation, signal processing, and electrooptic and microwave systems. He assisted in the design and implementation of the data telemetry and control systems for the Martha's Vineyard Coastal Observatory.

Marguerite K. McElroy studied sociology at Boston University prior to working in data processing for the accounting firm of Coopers \& Lybrand. She has worked in a variety of positions at Woods Hole Oceanographic Institution, Woods Hole, MA, since 1972. On this project she was responsible for permitting and liaison to state, federal and local agencies as well as involved in writing the specifications, reviewing the contractor proposals, installation logistics and field work. She is currently acting as observatory operations manager and particularly enjoys doing the educational outreach work.

Carlton W. Grant has worked at Woods Hole Oceanographic Institution, Woods Hole, MA, since 1958 where he has spent many years providing at-sea operation and maintenance support for a wide variety of ocean sampling equipment for a wide range of oceanographic research disciplines. He currently holds the position of Senior Engineering Assistant and is head technician for the Oceanographic Systems Lab (OSL). He works with the design engineers in OSL on the development, construction and testing of electro-mechanical components of prototype oceanographic equipment, instruments and underwater vehicles. He serves as head technician for the Martha's Vineyard Coastal Observatory and implemented the electrical engineering designs for the meteorological mast, oceanic node, and shore lab power.

Jonathan Ware received the B.S. degree in electrical engineering and the M.S. degree in ocean engineering from the University of New Hampshire in 1993 and 1995, respectively.

He currently holds an appointment as an Engineer in the Advanced Engineering Lab at the Woods Hole Oceanographic Institution, Woods Hole, MA. His research interests include instrumentation and data telemetry system design. He was responsible for instrumentation at the meteorological mast and offshore node and assisted in the design and implementation of data acquisition, data telemetry and control systems for the Martha's Vineyard Coastal Observatory.

Sheila K. Hurst received the B.A. degree in journalism from the University of Massachusetts at Amherst in 1990.

She worked as a reporter before joining the administrative staff in the Applied Ocean Physics and Engineering Department at the Woods Hole Oceanographic Institution, Woods Hole, MA, in 1998. She assisted in the permitting and procurement process for the Martha's Vineyard Coastal Observatory (MVCO). She maintains the observatory web pages and provides documentation for users. She is currently working on the web interface for data products from the MVCO. 